\title{
Effectiveness of Maitland Spinal Mobilisation Therapy in the Treatment of Non-Specific Low Back Pain - a prospective study of clients attending a single treatment centre in the Republic of Ireland
}

Anthony Phelan ${ }^{1 *}$, Kate Phelan ${ }^{1}$ and Michelle Foley ${ }^{2}$

*Correspondence: anthonyphelan@gmail.com

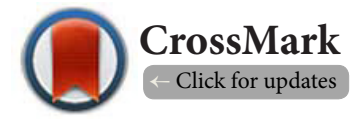

${ }^{1}$ Advance Physio, Dunmore Road, Waterford, Ireland.

${ }^{2} S c h o o l$ of Health Science, Waterford Institute of Technology, Cork Road, Waterford, Ireland

\begin{abstract}
Background: In Ireland the use of spinal mobilisation therapy (SMT) is a relatively new field in the management of pain in acute and chronic onset of low back pain (LBP) as individuals seek alternatives to other traditional clinical treatments. The aim of this study was to examine the effectiveness of a routine four-week course of spinal mobilisation in individuals experiencing non-specific LBP in a single practice. The main outcome variable was the reduction in severity of pain post treatment.

Methods: All clients attending for spinal mobilisation therapy using the Maitland method at a single site during the period of June 2018 to November 2019 were included in the study. Each client completed a pre-screening questionnaire, including pain scores obtained through the Numeric Rating Scale (NRS-11) and underwent a four-week treatment. Post screening questionaires were conducted following a four-week therapeutic treatment with an individual physical therapist. Data were coded and entered into SPSS version 21 for analysis. Wilcoxon signed rank tests were used to test pain scores pre and post treatment.

Results: 491 individuals had an initial consultation for LBP and 90 clients completed the recommended four-week programme. The most common symptom of LPB pain described by clients attending the clinical was sharp pain (55\%), followed by aching symptoms (33.6\%). The median length of LBP was 3 years and the median age was 44 years. In the 90 clients completing the four week programme a statistical significant difference was observed pre and post treatment $(\mathrm{p}<0.00) .88(97.8 \%)$ of clients indicated that they had a reduction in pain and one quarter of patients had complete elimination of pain following the four-week intervention.

Conclusions: The findings of this study indicate that manual therapy is a consideration in treatment of non-specific LBP and as an alternative to conventional treatment methods. Maintaining adherence to recommended treatment is a key challenge and may be strongly influenced by patients' expectations in recovery time and cost of treatment. Further and more in-depth research is needed to establish the success of SMT in treatment of non-specific LPB and in improving patient outcomes.

Keywords: Low back pain, Maitland method, Back injury, Spinal mobilisation therapy, Physical therapy
\end{abstract}

\section{Introduction}

Low back pain (LBP) is an unpleasant and debilitating condition of the musculoskeletal system with a lifetime prevalence reported to be as high as $84 \%$ of the adult population [1]. It is an important public health concern as it impacts on health service utilisation and is one of the leading causes of work re-

(C) 2020 Phelan et al; licensee Herbert Publications Ltd. This is an Open Access article distributed under the terms of Creative Commons Attribution License (http://creativecommons.org/licenses/by/3.0). This permits unrestricted use, distribution, and reproduction in any medium, provided the original work is properly cited. 
Phelan et al., Physical Therapy and Rehabilitation 2020,

http://www.hoajonline.com/journals/pdf/2055-2386-7-7.pdf

doi: $10.7243 / 2055-2386-7-7$

lated absenteeism and disability in Western populations [2-4] The growing number of people presenting with chronic low back pain, that is pain in the lower back lasting more than 12 weeks, is also increasing dramatically with increasing age [4]. A combination of problems, including physical and psychological factors attributed to LBP adds to the difficulty in diagnosis and management of the condition. Therapeutic management is thought to be most successful when the precise source of pain is identified [5]. In many cases, management of acute and chronic back pain is reliant on pain management therapy through opioid and non-opioid medication with limited high quality data on its benefits and harms $[6,7]$.

For the management of $L P B$, most clinical practice guidelines are focused recommendation to stay active, education, pain management with pharmaceuticals and physiotherapy [1]. However, treatment using physical therapy or spinal mobilisation therapy (SMT) for LBP is growing in popularity. One technique of SMT developed by Mr. Geoffrey Maitland, an Australian physiotherapist in the 1960's is directed towards the spine through "hands-on" slow and passive mobilisation of the spinal joints within the patient's range of motion [811]. However, the exact mechanism of action remains under some discussion. The most likely explanation is that it works through biomechanical and/or neurophysiological mechanisms focused on joint movement that improves the range of motion, decreased muscle spasm and decreased pain [10]. Clinical decision making using the Maitland method is guided by both mechanical and neurophysiological considerations and the individual's response to treatment over time.

Studies have shown that early intervention using physical therapy for acute LBP reduces healthcare utilisation and reduces opioid use [8]. Recent research has shown that SMT significantly improves symptoms of LBP, including pain, mobility and functionality [12-14]. A systematic review and meta-analysis of changes in pain sensitivity following SMT found favourable effects over other interventions on increasing pressure pain thresholds [15]. However, the use of physical therapies is shown to involve various approaches and variations to treatment and results demonstrating its effectiveness in treatment of non-specific LBP remain mixed. A recent Cochrane review on the use of physical therapy or spinal mobilisation therapy (SMT) in treatment of acute LBP suggest that treatment was no more effective than other recommended therapies. However, the authors highlight the lack of quality evidence available and indicate that SMT is a safe treatment option in the management of acute LBP [16].

In Ireland, the use of SMT is a relatively new field in the management of pain in acute and chronic onset of LBP as individuals seek alternatives to other traditional clinical treatments. There is limited data on use and effectiveness of SMT treatment in an Irish context. The assessment of treatment is very important to measure specific patient outcomes following SMT. The aim of this study was to examine the effectiveness of a routine four-week course of spinal mobilisation using Mait- land's mobilization in individuals experiencing non-specific LBP in a single practice. The main outcome variable was the reduction in severity of pain post treatment following SMT.

\section{Methods}

A service evaluation of treatment was carried out at a single physical therapy treatment centre located in the South East Region of Ireland. All patients attending the treatment centre for LBP between June2018 and November 2019 were included in the study.The main inclusion criteria were the presence of non-specific low back pain as the primary problem and consenting adults over the age of 18 years. Clients were excluded from the data set if they had attended the treatment centre for a primary problem not related to $L P B$, under the age of 18 years or had any particular history significant to bone weakening. There was no exclusion placed on gender, age, length of problem, past surgical treatment or use of medication for LBP. Each client was asked to provide written consent for use of their data for the purpose of measuring effectiveness of treatment in the management and treatment of LBP prior to treatment taking place. Data were excluded from the evaluation where consent was not obtained and treatment proceeded as normal. All clients were assessed and followed routine SMT treatment for their LBP complaint at the facility by a single physical therapist with greater than 20 years' experience.

A pre-assessment questionnaire aimed at collecting information on the location and duration of LBP, activities of daily living, use of regular medication and prior treatment was completed at the initial consultation (see Appendix 1). Participants were asked to rate the severity of their condition on a numeric pain rating scale [17] (see Figure 1). This 11-point numerical pain rating scale (NRS-11) tool is used in the measurement pain in which patients are asked to rate the intensity of their pain on a scale of 0 (no pain) to 10 (worst imaginable pain) [18]. The NRS-11 has shown good reliability and predictive validity as a measurement of pain intensity. It has also shown good responsiveness in its ability to detect changes in pain scores accurately when used in populations with conditions of LBP $[17,19]$.

Each client underwent an initial examination procedure conducted by a single therapist trained in Maitland Orthopaedic Manual Therapy. The Maitland therapy is based on treatment of pain and stiffness. This consists of assessment of active range of motion testing and accessory range of motion testing. The client's description of pain and stiffness is also used in the overall assessment. Pain dominant terminology expressed by clients include pain, burning, throbbing and aching. Stiffness dominant terms include stiff, tight, boring, stabbing shooting, restricted and limited. Clients grade of movement (pain and stiffness) are assessed and treatment is then provided based on grading by the physical therapist. When the client is pain dominant, grade I and II are used initially. Clients exhibiting stiffness are treated at grade III and IV. 
Phelan et al., Physical Therapy and Rehabilitation 2020,

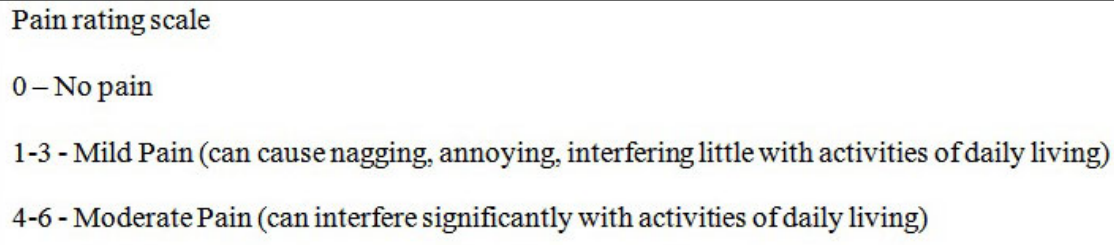

Activities of daily living include day to day activities such as eating, sleeping, dressing, walking, moving, independent care, working, exercising.

Figure 1. Pain rating Scale.

For further description of Maitland therapy see Table 1.

Table 1: Grades of movement Maitland orthopaedic method.

\begin{tabular}{lll}
\hline Grade & & Mobilisation \\
\hline GR I & $\begin{array}{l}\text { Small amplitude, short of } \\
\text { resistance (R1). R1 is the first } \\
\text { point in movement where } \\
\text { resistance is perceived by the } \\
\text { therapist. }\end{array}$ & $\begin{array}{l}\text { Postero-anterior } \\
\text { central, anteroposterior } \\
\text { central, postero- } \\
\text { anterior unilateral } \\
\text { and transverse } \\
\text { vertebral pressure } \\
\text { glide techniques of the } \\
\text { lumbar spine. }\end{array}$ \\
GR II & $\begin{array}{l}\text { Large amplitude, short of } \\
\text { resistance (R2). R2 represents } \\
\text { the limit of resistance in a } \\
\text { range of movement }\end{array}$ & $\begin{array}{l}\text { Unilateral rotation, } \\
\text { longitudinal, flexion, } \\
\text { straight leg raise, slump } \\
\text { or manual traction } \\
\text { oscillatory movements } \\
\text { of the lumbar spine. }\end{array}$ \\
GR III & $\begin{array}{l}\text { Large amplitude to 50\% of } \\
\text { R1-R2 }\end{array}$ & $\begin{array}{l}\text { Small Amplitude to 50\% of } \\
\text { R1-R2 }\end{array}$ \\
GR IV
\end{tabular}

A digital posture analysis of the frontal view of each patient was conducted on the initial consultation. Thetreatment procedure was then tailored to suit the findings of physical examination. This consisted principally of joint mobilisation and traction for dysfunctional joints, three times per week for a continuous four-week period. The mobilisation frequency was $50 \%$ per selected mobilisation technique. Grade I and II mobilisations were used for patients who indicated significant pain. The therapist transitioned to Grade III and IV mobilisations when the pain levels reduced, and the therapist deemed them tolerable. In addition, home exercises were provided based on the findings of the physical examination and consisted of the McKenzie's extension in lying. Patients were taught this exercise by the therapist, and were asked to do ten repetitions, three times per day. Lifestyle advice was also provided on an individual basis. All treatments were recorded in the clients notes to track progress and to ensure treatment proceeded in the correct order. A post-treatment questionnaire(see Appendix 2) was completed and clients were asked about to indicate their activities of daily living and regular medication use following the four-week Maitland SMT treatment programme. Participants were asked to rate the severity of their symptoms using the numeric pain rating scale post treatment.

Data was anonymised, coded and entered in to SPSS version 21 for analysis. Frequency and percentages were used to describe participants' demographics. The mean, median and standard deviation were used to summarise continuous data. Wilcoxon signed rank tests were used to test pain scores pre and post treatment. The statistical significance was set at the $5 \%$ level.A mixed ANOVA was used to compares mean distinctions in pre and post pain scores between groups based on age and gender.

\section{Findings}

Four hundred and ninety-one individuals had an initial consultation for LBP and 90 clients completed the recommended four-week programme. Those not completing the treatment were followed up and asked to indicate their reason for dropout. 45 participants indicated treatment was fully successful prior to completion of the recommended four-week time frame and a further five had indicated some pain relief before completion of the recommended treatment work period. Seven participants believed the treatment was not working for them, while a further five indicated that the cost was prohibitive. Fifteen participants had moved to treatment elsewhere or had been referred to a medical specialist during the four-week treatment period.The remainder of participants were not contactable, failed to return the call or did not wish to indicate the reason for dropout(see Figure 2). The demographic information of all clients is illustrated in Table 2. The most common symptom of non-specific LPB pain described by clients attending the clinical was sharp pain (55\%), followed 
Phelan et al., Physical Therapy and Rehabilitation 2020,

http://www.hoajonline.com/journals/pdf/2055-2386-7-7.pdf

Table 2: Demographic information on study participants.

\begin{tabular}{|c|c|c|}
\hline Demographic information & $\begin{array}{l}\text { All consultations } \\
\mathrm{N}=491\end{array}$ & $\begin{array}{l}\text { Completed } \\
\text { 4-week } \\
\text { Maitland } \\
\text { treatment } \\
\text { programme } \\
\text { n=90 }\end{array}$ \\
\hline Gender & Frequency (\%) & \\
\hline Male & $246(50.1)$ & $46(51.1)$ \\
\hline Female & 245(49.9) & $44(48.9)$ \\
\hline $\begin{array}{l}\text { Age (Mean, standard devia- } \\
\text { tion) }\end{array}$ & $45.90(17.4)$ & $44.9(17.5)$ \\
\hline Age (Median) & 44 & 43 \\
\hline \multicolumn{3}{|l|}{ Length of LBP complaint } \\
\hline Acute onset & $10(2.1)$ & 0 \\
\hline Less than 6 months & $222(45.8)$ & $35(38.8)$ \\
\hline 6-12months & $60(12.4)$ & $11(12.2)$ \\
\hline $1-2$ years & $57(11.8)$ & $14(15.5)$ \\
\hline $3-4$ years & $34(7.0)$ & $6(6.6)$ \\
\hline Greater than 5 years & $102(24.7)$ & $24(26.6)$ \\
\hline Unanswered & 6 & \\
\hline \multicolumn{3}{|c|}{ Length of long term LBP complaint } \\
\hline Median years (range) & $3(0-53)$ & $5(0-39)$ \\
\hline $\begin{array}{l}\text { Pain in other area } \\
\text { separate from LBP }\end{array}$ & Frequency (\%) & \\
\hline Yes & $213(44.4)$ & $53(58.8)$ \\
\hline No & $267(55.6)$ & $36(41.2)$ \\
\hline Unanswered & 11 & 1 \\
\hline \multicolumn{3}{|c|}{ Attended doctor in past 6 months with LPB } \\
\hline Yes & $217(44.3)$ & $46(51.1)$ \\
\hline No & $271(55.3)$ & $44(48.9)$ \\
\hline (Unanswered) & 3 & \\
\hline \multicolumn{3}{|c|}{ Taking regular medication for $\mathrm{LBP}$} \\
\hline Yes & $155(31.8)$ & $26(28.8)$ \\
\hline No & $322(68.2)$ & $64(71.2)$ \\
\hline Unanswered & 4 & \\
\hline \multicolumn{3}{|c|}{ Taking regular medication for conditions other than LBP } \\
\hline Yes & $217(44.6)$ & $38(42.2)$ \\
\hline No & $270(55.7)$ & $52(57.7)$ \\
\hline Unanswered & 4 & \\
\hline \multicolumn{3}{|c|}{ Symptoms of LBP pain experienced } \\
\hline Sharp pain & $270(55)$ & $45(50)$ \\
\hline Dull pain & $159(32.4)$ & $36(40)$ \\
\hline Boring pain & $32(6.5)$ & $9(10)$ \\
\hline Burning pain & $63(12.8)$ & $12(13.3)$ \\
\hline Numbing & $54(11.0)$ & $10(11.1)$ \\
\hline
\end{tabular}

Continuation of Table 2 .

\begin{tabular}{lll}
\hline Tingling & \multicolumn{1}{l}{$73(14.9)$} & $18(20)$ \\
Achy & $165(33.6)$ & $37(41.1)$ \\
\hline \multicolumn{2}{l}{ Description of LBP symptoms in the last six months } \\
\hline Getting better & $27(7.0)$ & $6(6.6)$ \\
Getting worse & $170(43.9)$ & $35(38.8)$ \\
About the same & $188(48.6)$. & $36(40)$ \\
Unanswered & 106 & 13 \\
\hline Diagnostic image procedure & & \\
\hline Yes & $178(38.9)$ & $43(47.7)$ \\
No & $280(61.1)$ & $45(50)$ \\
Unanswered & 33 & 2 \\
Surgical procedure for LBP & & 8() \\
Yes & $34(7.4)$ & $79(87.7)$ \\
No & $423(92.6)$ & 3 \\
Unanswered & 34 & \\
\hline
\end{tabular}

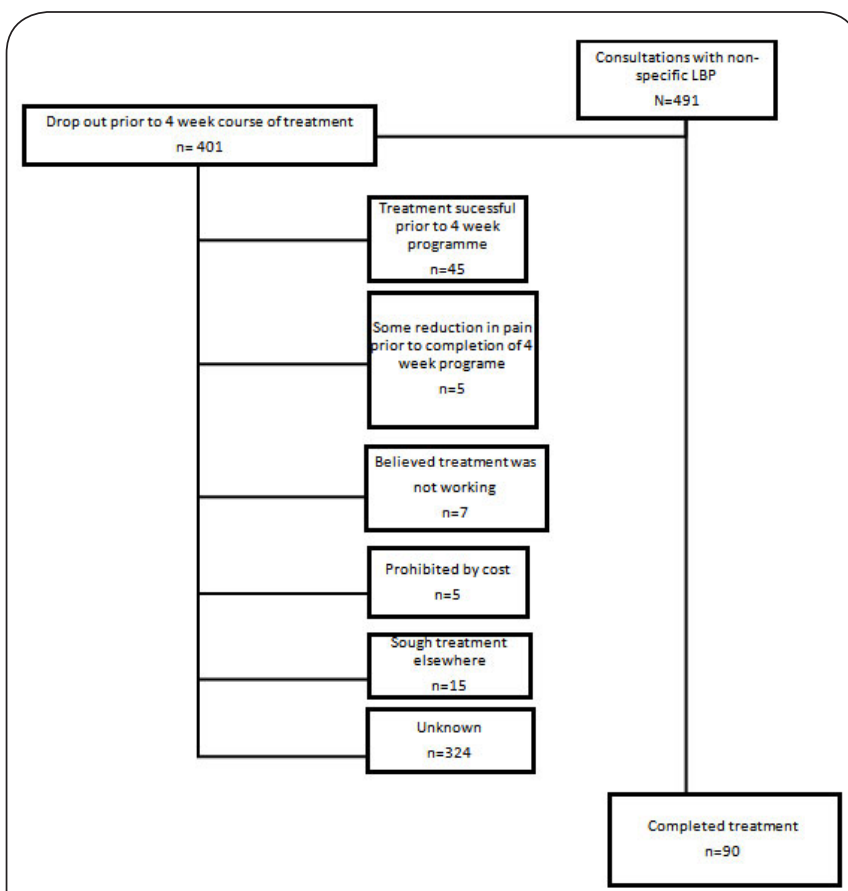

Figure 2. Showing number of participant consultations and reasons for dropout.

by aching symptoms (33.6\%). The median length of LBP was 3 years and the median age was 44 years.

In the 90 clients completing the four-week programme a Wilcoxon signed rank tests were used to test pain scores pre and post treatment. On a scale of $0-10$, where 0 was indicated as no pain and 10 severe pain, an average pain score was recorded at 5.38 (range 1-10) in the pre-treatment group. 
Post treatment average score was recorded as 2.14 (range $0-9)$. This was statistical significant at the $5 \%$ level $(p<0.00)$ (see Table 3). A mixed ANOVA was conducted to assess the impact of age and gender on participants' pain rating pre and post treatment. The model was found not violate the assumption of homogeneity. The main effect comparing age and gender was not statistically significant, $F(4,79)=1.177$, $p=0.327$, partial eta squared 0.056 ) suggesting no difference in the effectiveness of treatment based on these two variables. Overall the median improvement resulting in the reduction in pain scores (based on scale of 0-10) was to the magnitude of 3 points on the pain rating scale.

A number of outcomes were measured post treatment and $88(97.8 \%)$ of clients indicated that they had a reduction in pain and one quarter of patients had complete elimination of pain. The outcomes indicated by clients following the fourweek treatment are illustrated in Table 4.

\section{Discussion}

The assessment of treatment outcomes is very important in evaluating the improvement in LBP using physical therapies. Results from randomised and systematic reviews on the effectiveness of spinal mobilisation therapy indicate that some individuals respond very well to physical therapy while others report little or no improvement in LPB $[16,20]$. Our study showed that clients completing the recommended treatment

Table 3: Severity of pain score pre and post treatment.

\begin{tabular}{llll}
\hline N=90 & Pre-treatment & Post-treatment & $\begin{array}{l}\text { P-value } \\
\text { (Wilcoxon } \\
\text { signed rank) }\end{array}$ \\
\hline Mean (Range) & $5.38(1-10)$ & $2.14(0-9)$ & $0.00^{\star}$ \\
\hline
\end{tabular}

Table 4: Treatment outcomes.

\begin{tabular}{ll}
\hline $\begin{array}{l}\text { Outcomes after four week course of treatment } \\
\mathbf{n = 9 0}\end{array}$ & $\begin{array}{l}\text { Frequency } \\
\text { (\%) }\end{array}$ \\
\hline Reduction in pain & $88(97.8)$ \\
$\begin{array}{l}\text { Complete elimination of pain } \\
\text { Ability to perform tasks that could not be } \\
\text { performed prior to treatment }\end{array}$ & $58(25.5)$ \\
$\begin{array}{l}\text { Reduction in use of pain medication } \\
\text { (self-administered over the counter medicines }\end{array}$ & $51(56.6)$ \\
such as paracetamol, ibuprofen etc.) & \\
$\begin{array}{l}\text { Reduction in pain medication prescribed by the } \\
\text { GP/doctor }\end{array}$ & $18(20)$ \\
Complete elimination of pain medications & $27(30)$ \\
$\begin{array}{l}\text { Ability to exercise or exercise more frequently } \\
\text { Reduction in stress }\end{array}$ & $60(66.6)$ \\
Positive change in mood or levels of anxiety & $44(48.9)$ \\
Levels of positive well-being & $52(55.5)$ \\
\hline
\end{tabular}

of four weeks of Maitland's spinal mobilisation therapy were found to respond well to treatment resulting in a decrease in overall pain scores. Similarly with a randomized clinical trial comparing SMT to muscle relaxants for subacute LBP in a group of 191 participants over a two course of treatment found a reduction in pain in the group receiving mobilisation treatment in comparison to the control group [21]. However, the treatment group in this case had an onset of acute pain of two to six weeks. Similarly, a recent study comparing Maitland's postero-anterior mobilization and Mulligan's sustained natural apophyseal glide (SNAG) on pain, mobility, muscle activation and functional disability in subjects with chronic, non-specific low back pain found that both groups showed significant improvement for pain, range of motion, back extensor muscular activity and disability [22]. While clients were randomised into the two treatment groups in this study it only represents a very small sample size. However, a separate study concluded with similar findings, indicating both Maitland and Mulligan methods of SMT provided an improvement in range of motion and a reduction in pain for those with sacroiliac joint dysfunction [23].

While we found that age and gender was not shown to have any significant effect on the reduction of pain scores, greater subgroup analysis would be needed to identify specific populations that are likely to benefit from SMT, including the impact of treatment on the length of the long term problem. Women typically have a smaller sacrum joint surface area in comparison to men, resulting in a higher concentration of stresses across the joint. The sacrum is also wider with greater curvature and is tilted backward in women, which may cause problems in the sacroiliac joint [24]. Changes in hormone levels and pregnancy is also associated with increased presentation of LBP in women. There is some limited evidence to suggest the Maitland method is effective in improving pain and functionality in younger adults with chronic LBP [25]. However, increasing age is positively associated with higher level of spinal degradation and therefore younger people may respond better to treatment for physiological reasons.

In our audit, clients participating in the recommended fourweek programme showed a number of improvements in quality of life indicators. Over three quarters of participants indicated an ability to perform tasks that they could not perform prior to treatment and improvements in their ability to perform exercise post treatment. This may concur with the findings of a recent systematic review and meta-analysis of the benefits and harms of SMT for treatment of chronic LPB. The authors conclude that while the quality of evidence varied suggesting that SMT does not result in clinically better effects for pain relief there appears to be better short term improvement in function compared with other treatment methods [26]. Almost half of all participants in the current study indicted a reduction in levels of stress, positive change in mood and improvements in the levels of well-being. Participants also reported less use of over the counter (OTC) pain medication 
Phelan et al., Physical Therapy and Rehabilitation 2020,

http://www.hoajonline.com/journals/pdf/2055-2386-7-7.pdf

doi: $10.7243 / 2055-2386-7-7$

and use of prescription medication. A double-blinded randomized controlled trial in comparison with diclofenac and placebo and spinal mobilisation indicated that participants experienced better quality of life after the spinal mobilisation when compared to diclofenac [27].

There are a number of limitations in the current study. It was limited by the number of clients that did not complete the recommended treatment and therefore sub groups analysis was not conducted due to the small sample size. The analysis is also limited to a subgroup of acute non-specific LBP which may or may not have other health problems. Therefore, it is recommended that some caution is exercised in the generalisation of these results to the wider population. The therapy was conducted by a single therapist and this may have been advantageous in removing some of the variation that exists in mobilisations techniques used in spinal therapy treatment. There may be potential for responder bias in reporting of pain score pre and post treatment. While this study showed positive improvements in pain scores, it was conducted as an audit of current practice. Double-blinded, randomizedcontrolled, clinical trials are the recommended gold standard in measuring treatment outcomes. More detailed data collection to record the exact location of pain and its extension in the peripheries, improvements in strength, sensory changes, reflex changes, body max index and adherence to exercise is recommended in any future studies. Nonetheless, the study showed that adherence to the treatment programme over the four-week period was very successful in alleviating pain associated with non-specific LBP.

\section{Conclusion}

The findings of this audit indicate that manual therapy using the Maitland method is a consideration in treatment of LBP and as an alternative to conventional treatment methods. Maintaining adherence to recommended treatment is a key challenge and may be strongly influenced by cost of treatment $[\mathbf{2 8}, \mathbf{2 9}]$. The cost of treatment is not covered under the general medical scheme (GMS) in Ireland and clients must pay for the full course of treatment. While cost is a consideration in adherence to treatment, other factors may improve the completion of recommended treatment. Assessment of patients' knowledge and understanding of the problem and expected outcomes may improve adherence. It is well recognised that clear and effective communication between health professionals and their clients develops trust in the therapeutic relationship $[\mathbf{2 8 , 3 0}]$. The use of spinal mobilisation as a strategy in the treatment of LBP requires further debate and study in Ireland with the inclusion of stakeholders from the medical professions.

\section{List of abbreviations}

LBP: Low back pain

SMT: Spinal mobilisation therapy

OTC: Over the Counter

\section{Additional files \\ Appendix 1 \\ Appendix 2}

\section{Competing interests}

The authors declare that they have no competing interests.

Authors' contributions

\begin{tabular}{|l|c|c|c|}
\hline Authors' contributions & AP & KP & MF \\
\hline Research concept and design & $\checkmark$ & -- & $\checkmark$ \\
\hline Collection and/or assembly of data & $\checkmark$ & $\checkmark$ & $\checkmark$ \\
\hline Data analysis and interpretation & $\checkmark$ & -- & $\checkmark$ \\
\hline Writing the article & $\checkmark$ & $\checkmark$ & $\checkmark$ \\
\hline Critical revision of the article & -- & -- & $\checkmark$ \\
\hline Final approval of article & $\checkmark$ & -- & \\
\hline Statistical analysis & -- & -- & $\checkmark$ \\
\hline
\end{tabular}

\section{Publication history}

Editor: Gordon John Alderink, Grand Valley State University, USA.

Received: 07-July-2020 Final Revised: 25-Aug-2020

Accepted: 07-Sep-2020 Published: 14-Sep-2020

\section{References}

1. Balagué $F$, Mannion AF, Pellisé F, Cedraschi $C$. Non-specific low back pain. The Lancet. 2012;379(9814):482-91.

2. Wong AY, Karppinen J, Samartzis D. Low back pain in older adults: risk factors, management options and future directions. Scoliosis and spinal disorders. 2017;12(1):14.

3. Kigozi J, Konstantinou K, Ogollah R, Dunn K, Martyn L, Jowett S. Factors associated with costs and health outcomes in patients with Back and leg pain in primary care: a prospective cohort analysis. BMC health services research. 2019;19(1):406.

4. Hartvigsen J, Hancock MJ, Kongsted A, Louw Q, Ferreira ML, Genevay $S$, et al. What low back pain is and why we need to pay attention. The Lancet. 2018;391(10137):2356-67.

5. Allegri M, Montella S, Salici F, Valente A, Marchesini M, Compagnone C, et al. Mechanisms of low back pain: a guide for diagnosis and therapy. F1000Res. 2016;5:F1000 Faculty Rev-530.

6. Krebs EE, Gravely A, Nugent S, Jensen AC, DeRonne B, Goldsmith ES, et al. Effect of Opioid vs Nonopioid Medications on Pain-Related Function in Patients With Chronic Back Pain or Hip or Knee Osteoarthritis Pain: The SPACE Randomized Clinical TrialOpioid vs Nonopioid Medications on Pain-Related FunctionOpioid vs Nonopioid Medications on Pain-Related Function. JAMA. 2018;319(9):872-82.

7. Bernstein IA, Malik Q, Carville S, Ward S. Low back pain and sciatica: summary of NICE guidance. BMJ. 2017;356:i6748.

8. Arnold E, La Barrie J, DaSilva L, Patti M, Goode A, Clewley D. The impact of timing of physical therapy for acute low back pain on health services utilization: a systematic review. Archives of Physical Medicine and Rehabilitation. 2019Jul 1;100(7):1324-38

9. Hurley DA, McDonough SM, Baxter GD, Dempster M, Moore AP. A descriptive study of the usage of spinal manipulative therapy techniques within a randomized clinical trial in acute low back pain. Manual Therapy. 2005 Feb 1;10(1):61-7.

10. Bialosky JE, Simon CB, Bishop MD, George SZ. Basis for spinal manipulative therapy: a physical therapist perspective. Journal of Electromyography and Kinesiology. 2012 Oct 1;22(5):643-7.

11. Maitland GD. Maitland's vertebral manipulation. Elsevier ButterworthHeinemann; 2005. 
Phelan et al., Physical Therapy and Rehabilitation 2020,

12. Khan S, Al Torairi N, Shamsi S. Comparative study of Snags and Maitland's Moblization in chronic low back pain. European Journal of Physical Education and Sport Science. 2018 Oct 24.

13. Mushtaq K, Waqas S, Asim HM. Effectiveness of Maitland Grade I and II Spinal Mobilization for Chronic Low Back Pain. Annals of King Edward Medical University. 2018 Mar 26;24(1):577-80.

14. Javaherian M, Tajali SB, Moghaddam BA, Keshtkar AA, Azizi M. Immediate effects of Maitland mobilization and Mulligan techniques on flexion and extension range of motion in patients with chronic nonspecific low back pain: a randomized pilot study. Journal of Modern Rehabilitation. 2017 Apr 1:127-32.

15. Coronado RA, Gay CW, Bialosky JE, Carnaby GD, Bishop MD, George SZ. Changes in pain sensitivity following spinal manipulation: a systematic review and meta-analysis. Journal of Electromyography and Kinesiology. 2012 Oct 1;22(5):752-67.

16. Rubinstein SM, Terwee CB, Assendelft WJ, de Boer MR, van Tulder MW. Spinal manipulative therapy for acute low-back pain. Cochrane Database of Systematic Reviews. 2012 Sep 12;2012(9):CD008880.

17. Childs JD, Piva SR, Fritz JM. Responsiveness of the Numeric Pain Rating Scale in Patients with Low Back Pain. Spine. 2005;30(11):1331-4.

18. Price DD, Staud R, Robinson ME. How should we use the visual analogue scale (VAS) in rehabilitation outcomes? II: Visual analogue scales as ratio scales: an alternative to the view of Kersten et al. Journal of rehabilitation medicine: official journal of the UEMS European Board of Physical and Rehabilitation Medicine. 2012 Sep;44(9):800.

19. Farrar JT, Young Jr JP, LaMoreaux L, Werth JL, Poole RM. Clinical importance of changes in chronic pain intensity measured on an 11-point numerical pain rating scale. Pain. 2001 Nov 1;94(2):149-58.

20. Assendelft WJJ, Morton SC, Yu EI, Suttorp MJ, Shekelle PG. Spinal Manipulative Therapy for Low Back Pain: A Meta-Analysis of Effectiveness Relative to Other Therapies. Annals of Internal Medicine. 2003;138(11):871-81.

21. Hoiriis KT, Pfleger B, McDuffie FC, Cotsonis G, Elsangak O, Hinson R, et al. A Randomized Clinical Trial Comparing Chiropractic Adjustments to Muscle Relaxants for Subacute Low Back Pain. Journal of Manipulative and Physiological Therapeutics. 2004;27(6):388-98.

22. Ali MN, Sethi K, Noohu MM. Comparison of two mobilization techniques in management of chronic non-specific low back pain. Journal of Bodywork and Movement Therapies. 2019 Oct 1;23(4):918-23.

23. Kaur H, Sharma M, Hazari A. Effectiveness of Maitland Mobilization and Mulligan Mobilization in Sacroiliac Joint Dysfunction: A Comparative Study. Critical Reviews in Physical and Rehabilitation Medicine. 2019;31(2).

24. Joukar A, Shah A, Kiapour A, Vosoughi AS, Duhon B, Agarwal AK, Elgafy $\mathrm{H}$, Ebraheim N, Goel VK. Sex specific sacroiliac joint biomechanics during standing upright: a finite element study. Spine. 2018 Sep 15;43(18):E1053-60.

25. daGama eSilva Ferreira M, deMèlo LC, deMendonça HC, Cabral KD, Rodrigues FT, Gomes doNascimento LS, Guerino MR, Ferreira AP. Maitland in chronic lumbar pain of young adults improves pain and functionality. Manual Therapy, Posturology \& Rehabilitation Revista Manual Therapy. 2017;15.

26. Rubinstein SM, De Zoete A, Van Middelkoop M, Assendelft WJ, De Boer MR, Van Tulder MW. Benefits and harms of spinal manipulative therapy for the treatment of chronic low back pain: systematic review and metaanalysis of randomised controlled trials. BMJ. 2019 Mar 13;364.

27. von Heymann WJ, Schloemer P, Timm J, Muehlbauer B. Spinal HighVelocity Low Amplitude Manipulation in Acute Nonspecific Low Back Pain: A Double-Blinded Randomized Controlled Trial in Comparison With Diclofenac and Placebo. Spine. 2013;38(7):540-8.

28. Martin LR, Williams SL, Haskard KB, Dimatteo MR. The challenge of patient adherence. Therapeutic Clinical Risk Management.
2005;1(3):189-99.

29. Connolly S, Wren M-A. The 2011 proposal for Universal Health Insurance in Ireland: Potential implications for healthcare expenditure. Health Policy. 2016;120(7):790-6.

30. Aslani P, Ahmed R, da Costa FA. The Role of Adherence in Pharmaceutical Care. In: Alves da Costa F, van Mil JWF, Alvarez-Risco A, editors. The Pharmacist Guide to Implementing Pharmaceutical Care. Cham: Springer International Publishing; 2019. p. 41-57.

\section{Citation:}

Phelan A, Phelan K and Foley M. Effectiveness of Maitland Spinal Mobilisation Therapy in the Treatment of NonSpecific Low Back Pain - a prospective study of clients attending a single treatment centre in the Republic of Ireland. Phys Ther Rehabil. 2020; 7:7.

http://dx.doi.org/10.7243/2055-2386-7-7 